\title{
Desenvolvimento do Pinus elliottii e do Eucalyptus tereticorni consorciado com plantas de cobertura, em solos degradados por arenização
}

\author{
Growth of Pinus elliottii and Eucalyptus tereticornis associated with cover plants, in degraded soils by \\ arenization
}

\author{
Ana Paula Moreira Rovedder ${ }^{{ }^{*}}$ Flávio Luiz Foletto Eltz ${ }^{\mathrm{I}}$
}

\section{RESUMO}

Espécies florestais exóticas têm sido utilizadas para a recuperação de solos degradados, auxiliando no controle da erosão hídrica e eólica. No sudoeste do Rio Grande do Sul, foram testados o Pinus elliotii Engelm. e o Eucalyptus tereticornis Sm., com o objetivo de avaliar o crescimento destas espécies e testar sua capacidade na contenção do fenômeno da arenização. Os tratamentos consistiram do plantio das duas espécies sobre o solo degradado por arenização (SD), sobre o campo nativo (C), sobre o campo nativo associado a plantas de cobertura $(C+P C)$ e sobre o solo degradado com plantas de cobertura $(S D+P C)$. Como plantas de cobertura, foram testadas a aveia preta (Avena strigosa Schieb.) e um tremoço nativo do ecossistema dos campos sulinos, o Lupinus albescens H. et Arn.. Determinaram-se o percentual de sobrevivência inicial, a altura, o diâmetro à altura do colo (DAC) e o fator de produtividade (FP) das espécies florestais, aos 30 dias, seis meses e 12 meses após plantio. O experimento foi conduzido em delineamento inteiramente casualizado, e os resultados submetidos ao teste de Duncan, em um nível de 5\% de probabilidade de erro. Em relação à sobrevivência inicial, apenas o pínus apresentou diferenças estatísticas, com menor percentual no tratamento $C+P C$. Os resultados demonstraram que o eucalipto beneficiou-se do consórcio com plantas de cobertura, enquanto o pínus apresentou maior sensibilidade à competição interespecífica.

Palavras-chave: plantas de cobertura, recuperação de solos, revegetação, erosão eólica.

\section{ABSTRACT}

Exotic forest species have been used for soil reclamation, as well as helping in the control of water and wind erosion. In the southwest of Rio Grande do Sul state, Brazil, the Pinus elliotii Engelm. and the Eucalyptus tereticornis Sm., were tested with the objective of evaluating the growth of these species and testing its capacity for reducing the arenization process. The treatments consisted of planting the two species on the degraded soil by arenization (DS), on the native grassfield $(C)$, on the native grassfield associated with cover crops $(C+P C)$ and on the degraded soil associated with cover crops $(D S+P C)$. As cover crops were tested the black oat (Avena strigosa Schieb.) and a Lupinus native from the southern grassfields ecosystem, the Lupinus albescens $H$. et Arn.. The plants survival rate, height, basal diameter and the productivity factor of the forest species were obtained in the thirty days, six months and twelve months after planting. The experiment was conduced in completely randomized design, and results submited to Duncan test, in level of $5 \%$ error probability. In relation to initial survival, only pine presented significative differences, with lesser percentual in the treatment $C+P C$. Results showed that Eucalyptus benefited from the consortium with cover crops, while pine presented greater sensibility to interespecific competition.

Key words: cover plants, soil reclamation, revegetation, wind erosion

\section{INTRODUÇÃo}

O plantio de espécies florestais tem se firmado como uma alternativa para conter processos erosivos e recuperar áreas degradadas e para reequilibrar a ciclagem de minerais em solos empobrecidos pelo uso intensivo (COSTA, 1990; LIMA, 1996). O fenômeno de degradação gera condições físicas, químicas e biológicas desfavoráveis no solo (RESENDE \& KONDO, 2001). Para recuperar física, química e biologicamente o solo, a técnica de revegetação promove o retorno de diversas funções do ecossistema afetado. A vegetação pode estabilizar a superfície e

IDepartamento de Solos, Universidade Federal de Santa Maria, (UFSM), Santa Maria, RS, Brasil. *Endereço para correspondência:

Rua Barão do Triunfo, 459, Rosário, 97010-070, Santa Maria, RS, Brasil. E-mail: anarovedder@yahoo.com.br. 
intensificar o processo pedogenético pela atuação dos compostos orgânicos na estrutura dos minerais e pela incorporação do próprio material orgânico ao solo, mesmo que a estrutura do solo não seja reconstruída (KLAMT \& SCHNEIDER, 1995).

A associação com espécies de ciclo mais curto e elevado aporte de massa verde, como as culturas de cobertura, adquire grande importância, já que os benefícios, propiciados pelo povoamento florestal, ocorrem em longo prazo. Diversos estudos utilizando este tipo de associação têm demonstrado resultados positivos na contenção do processo erosivo, no incremento da ciclagem de nutrientes e no retorno da fauna do solo (SILVA et al., 2001; ROVEDDER, 2003).

A escolha das espécies a serem empregadas na recuperação de áreas degradadas é fundamental para a obtenção de resultados positivos. Tais espécies devem ser rústicas o suficiente para estabelecerem-se em ambientes desfavoráveis, apresentando agressividade na competição com outras espécies, facilidade de estabelecimento e rápido desenvolvimento (DIAS \& GRIFFITH, 1998; RESENDE \& KONDO, 2001).

No sudoeste do Rio Grande do Sul, a vegetação de pradarias mistas desenvolve-se sobre solos extremamente arenosos, suscetíveis à degradação pelo fenômeno da arenização, no qual a cobertura vegetal é retirada pela ação da erosão hídrica e eólica. Nesses locais, formam-se bancos de areia, movimentados pela ação do vento, e que são regionalmente conhecidos como areais ou campos de areia, resultantes da fragilidade natural do ecossistema, aliada à atividade agropecuária intensiva (AB'SABER, 1995; SUERTEGARAY, 1995).

Tentativas de contenção da erosão vêm utilizando espécies exóticas de rápido crescimento, pela necessidade de proteção e cobertura emergenciais, a fim de não se permitir que a arenização avance. Espécies como o pinus e o eucalipto têm demonstrado facilidade de adaptação aos solos da região, já degradados ou em vias de degradação (SOUTO, 1984). Muitas vezes, porém, conseqüências advindas da erosão eólica, como o efeito abrasivo das partículas em suspensão, a exposição de raízes pela perda de solo e o soterramento na fase de deposição das partículas, ocasionam a morte das mudas ou prejudicam o crescimento das mesmas.

Em fases iniciais de recuperação de áreas degradadas, o objetivo prioritário é a reabilitação da função e dos serviços do ecossistema. Isso significa que muitas vezes torna-se impossível reabilitar a estrutura original de um ecossistema em um primeiro momento, sendo urgente a amenização dos agentes impactantes por meio da cobertura imediata do solo.
No presente estudo, objetivou-se avaliar o potencial de desenvolvimento do Pinus elliottii Engelm. (pinus) e do Eucalyptus tereticornis Sm. (eucalipto) associados às culturas de cobertura Avena strigosa Schieb. (aveia preta) e Lupinus albescens H. et Arn. (tremoço nativo) na revegetação de áreas arenizadas. A hipótese do estudo é a de que a área de campo, ainda não degradada e, portanto, sem os efeitos nocivos da erosão eólica sobre o crescimento das mudas, apresenta melhores condições para iniciar-se a revegetação, principalmente devido à retenção de umidade, conteúdo de matéria orgânica e amenização dos efeitos erosivos.

\section{MATERIAL E MÉTODOS}

O presente trabalho foi desenvolvido nos anos de 2001 e 2002, no município de Alegrete (RS), o qual está inserido na região de ocorrência dos areais, que compreende o sudoeste do Rio Grande do Sul, entre as latitudes de $29^{\circ} 00^{\prime} \mathrm{S}$ e $31^{\circ} 00^{\prime} \mathrm{S}$ e entre as longitudes de $54^{\circ} 30^{\prime} \mathrm{W}$ e $58^{\circ} 45^{\prime} \mathrm{W}$, fazendo parte da região fisiográfica da Campanha Gaúcha. O clima é Cfa, segundo Koeppen, subtropical úmido, sem uma estação seca definida, com uma média de precipitações anuais de $1.400 \mathrm{~mm}$. A região apresenta ventos com velocidades menores no período de outono-inverno, intensificando-se no de período primavera-verão (SOUTO, 1984; SUERTEGARAY, 1998). O relevo é suave ondulado, com áreas planas em decorrência do desgaste geológico, compondo uma superfície aplainada inferior (SOUTO, 1984), contrastando com os platôs de arenito silicificado da paisagem regional. A vegetação apresenta características xeromórficas, de forte influência edáfica, testemunha de um período semi-árido ou semi-úmido estepário, que sofreu umidificação a partir do Holoceno Médio, contudo insuficiente para eliminar a influência do período anterior na paisagem moderna (MEDEIROS et al., 1995; SUERTEGARAY, 1995).

A arenização do solo no local do estudo iniciou-se há aproximadamente 15 anos, decorrente do intenso pisoteio de bovinos, nunca tendo sido utilizado com cultivos agrícolas. O areal possui 10 hectares, medidos por recobrimento com sistema de posicionamento global (GPS). O solo do local de estudo é um Neossolo Quartzarênico distrófico (EMBRAPA, 1999).

As espécies florestais testadas foram o pínus e o eucalipto e, como culturas de cobertura, utilizou-se a aveia preta e o tremoço nativo. Os tratamentos foram: pínus e eucalipto plantados em parcelas de campo nativo com plantas de cobertura 
(C+ PC); solo degradado com plantas de cobertura (SD + PC); campo nativo sem plantas de cobertura(C) e solo degradado sem plantas de cobertura (SD), totalizando oito tratamentos, com quatro repetições cada.

Foram estabelecidas parcelas com dimensões de 10 metros de largura e 50 metros de comprimento, com metade da sua área sobre o campo e a outra metade sobre o areal, em delineamento inteiramente casualisado. Como freqüência de amostragem, utilizaram-se as cinco primeiras plantas das três fileiras centrais de cada parcela, totalizando 15 plantas por parcela e eliminando-se o efeito de bordadura das parcelas.

A aveia preta foi semeada em junho de 2001, com o plantio das espécies florestais sendo realizado logo a seguir. Em 2002, foi implantado o segundo cultivo de cobertura, com um consórcio aveia preta e tremoço nativo. As mudas de pínus e eucalipto foram cultivadas em tubetes de $12,5 \mathrm{~cm}$ e levadas para o campo no sistema rocambole. O plantio foi realizado em espaçamento $2 \mathrm{x}$ $2 \mathrm{~m}$, com um total de 65 plantas por parcela. A adubação foi feita na cova, com $100 \mathrm{~g}$ de adubo NPK 5-30-15, equivalente a $250 \mathrm{~kg} \mathrm{ha}^{-1}$, e $60 \mathrm{~g}$ de calcário dolomítico, equivalente a $150 \mathrm{~kg} \mathrm{ha}^{-1}$. Após o plantio, a área experimental foi isolada com tela de malha $6 \mathrm{~cm}$, com $1 \mathrm{~m}$ de altura, enterrada $30 \mathrm{~cm}$ no solo para evitar a entrada e o pisoteio de animais, principalmente bovinos e lebres. O controle de formigas foi realizado quinzenalmente de março de 2001 a novembro de 2002.

Avaliou-se a taxa de sobrevivência das plantas de pínus e eucalipto aos 12 meses após o plantio. Os valores percentuais das plantas sobreviventes foram transformados para arco seno, em que $\mathrm{X}=\%$ de plantas sobreviventes, para análise da variância. Os resultados foram submetidos à análise de variância e ao teste de Duncan em um nível de 5\% de probabilidade de erro.

Para a avaliação do crescimento das plantas de pínus e eucalipto, utilizaram-se os parâmetros altura (h), diâmetro à altura do colo (DAC) e fator de produtividade (FP), conforme proposto por CANTARELI (2002). As medições desses parâmetros foram realizadas aos 30 dias, 6 e 12 meses após o plantio. Aplicou-se o teste de Duncan para as médias dos valores obtidos para os três parâmetros de crescimento, nas três épocas de medições, para cada espécie florestal.

\section{RESULTADOS E DISCUSSÃO}

A tabela 1 apresenta os valores percentuais de sobrevivência do eucalipto e do pínus aos 12 meses após o plantio. Nas condições do experimento, constatou-se que não houve influência negativa da
Tabela 1 - Sobrevivência do Eucalyptus tereticornis e do Pinus elliottii aos 12 meses após o plantio sobre o campo nativo com plantas de cobertura (C+PC), solo degradado com plantas de cobertura (SD+PC), campo nativo (C) e solo degradado (SD), em Alegrete, RS (média de 4 repetições).

\begin{tabular}{lcc}
\hline \multirow{2}{*}{ Tratamento } & \multicolumn{2}{c}{ Sobrevivência } \\
\cline { 2 - 3 } & $\begin{array}{c}\text { Eucalyptus } \\
\text { tereticornis }\end{array}$ & Pinus elliottii \\
& $91 \mathrm{a}^{1}$ & \\
C + PC & $90 \mathrm{a}$ & $33 \mathrm{~b}^{1}$ \\
SD + PC & $100 \mathrm{a}$ & $83 \mathrm{a}$ \\
$\mathrm{C}$ & $83 \mathrm{a}$ & $73 \mathrm{a}$ \\
SD & & $63 \mathrm{a}$ \\
\hline
\end{tabular}

${ }^{1}$ Médias seguidas pela mesma letra na coluna não diferem entre si pelo teste de Duncan em nível de 5\% de probabilidade de erro.

vegetação herbácea (culturas de cobertura e campo nativo) na sobrevivência de plantas de eucalipto. Embora a ausência de diferença estatística, a presença de cobertura herbácea nos tratamentos C + PC, C e SD + PC parece ter influenciado beneficamente a sobrevivência do eucalipto, provavelmente devido à amenização da temperatura do solo e da abrasão decorrente do transporte de partículas pela erosão eólica. Em alguns estudos envolvendo sistemas agroflorestais e silvipastoris com eucalipto, também não foram encontrados prejuízos à sobrevivência do eucalipto quando consorciado a espécies de porte herbáceo (SCHREINER \& BALLONI, 1986).

O pínus apresentou baixas taxas de sobrevivência, com uma média de 63\% (Tabela 1). A baixa taxa de sobrevivência no campo com plantas de cobertura $(\mathrm{C}+\mathrm{PC})$ pode caracterizar a influência de competição interespecífica com a cobertura herbácea do tratamento. MONTENEGRO (1998), em experimento de controle de plantas daninhas em um povoamento de Pinus taeda, não encontrou diferenças significativas na taxa de sobrevivência durante os primeiros 12 meses.

A tabela 2 apresenta os valores de crescimento em diâmetro à altura do colo, altura e fator de produtividade das duas espécies, aos 30 dias, 6 e 12 meses após plantio. O solo degradado com plantas de cobertura (SD + PC) destacou-se como o tratamento, que permitiu o maior crescimento do eucalipto, apresentando diferenças significativas em altura e produtividade em relação aos demais tratamentos. É notável a diferença, principalmente, em fator de produtividade, do eucalipto no tratamento SD + PC. Estes resultados sugerem que a cultura de cobertura, quando utilizada sobre o solo degradado, não compete com o eucalipto e que este se beneficia do seu efeito 
Tabela 2 - Diâmetro à altura do colo (DAC), altura e fator de produtividade (FP) para Eucalyptus tereticornis e Pinus elliottii aos 30 dias, 6 e 12 meses de idade, em Alegrete, RS (média de 4 repetições).

\begin{tabular}{|c|c|c|c|c|c|c|}
\hline \multirow{2}{*}{ Tratamento } & \multicolumn{2}{|c|}{ DAC } & \multicolumn{2}{|c|}{ Altura } & \multicolumn{2}{|c|}{ FP } \\
\hline & E. tereticornis & P. elliottii & E. tereticornis & P. elliottii & E. tereticornis & P. elliottii \\
\hline \multicolumn{7}{|c|}{30 dias } \\
\hline & \multicolumn{4}{|c|}{$\mathrm{cm}$} & \multicolumn{2}{|c|}{$\mathrm{cm}^{3}$} \\
\hline$C+P C$ & $0,35 a^{2}$ & $0,43 \mathrm{a}$ & $39,60 \mathrm{a}$ & $42,20 \mathrm{a}$ & $5,10 \mathrm{a}$ & 7,43 a \\
\hline $\mathrm{SD}+\mathrm{PC}$ & 0,33 a & 0,39 a & $38,70 \mathrm{a}$ & $43,30 \mathrm{a}$ & $5,40 \mathrm{a}$ & 8,56 a \\
\hline $\mathrm{C}$ & 0,38 a & $0,42 \mathrm{a}$ & 39,30 a & 39,10 a & $4,49 a b$ & $6,42 \mathrm{~b}$ \\
\hline SD & $0,33 \mathrm{a}$ & $0,41 \mathrm{a}$ & $\begin{array}{l}35,00 \mathrm{a} \\
6 \text { meses }\end{array}$ & $44,30 \mathrm{a}$ & $4,22 \mathrm{~b}$ & 8,79 a \\
\hline$C+P C$ & $1,86 b^{2}$ & $0,70 \mathrm{a}$ & 111,60 c & $49,30 \mathrm{a}$ & 522,55 c & $22,04 \mathrm{~b}$ \\
\hline $\mathrm{SD}+\mathrm{PC}$ & $2,84 \mathrm{a}$ & $0,81 \mathrm{a}$ & $151,00 \mathrm{a}$ & $50,30 \mathrm{a}$ & $1408,00 \mathrm{a}$ & $37,05 \mathrm{a}$ \\
\hline C & $1,98 a b$ & $0,58 \mathrm{~b}$ & $114,00 \mathrm{c}$ & $46,50 \mathrm{a}$ & $565,00 \mathrm{c}$ & $16,567 \mathrm{~b}$ \\
\hline SD & 2,59 a & 0,90 a & $138,00 \mathrm{~b}$ & $52,40 \mathrm{a}$ & $868,00 \mathrm{~b}$ & 43,502 a \\
\hline \multicolumn{7}{|c|}{12 meses } \\
\hline$C+P C$ & $3,61 b^{2}$ & $1,15 \mathrm{c}$ & $188,40 \mathrm{~b}$ & $56,20 \mathrm{~b}$ & 2886,79 b & 91,25 c \\
\hline $\mathrm{SD}+\mathrm{PC}$ & 5,7 a & $1,54 \mathrm{~b}$ & 306,90 a & $58,60 \mathrm{~b}$ & 10839,73 a & 240,07 b \\
\hline C & $3,68 b$ & $1,56 \mathrm{~b}$ & $204,80 \mathrm{~b}$ & $60,70 \mathrm{~b}$ & $3319,13 \mathrm{~b}$ & $250,0 \mathrm{~b}$ \\
\hline SD & 4,73 ab & $1,82 \mathrm{a}$ & $191,10 \mathrm{~b}$ & $67,10 \mathrm{a}$ & 5486,25 b & 279,53 a \\
\hline
\end{tabular}

$\mathrm{C}+\mathrm{PC}=$ campo nativo com plantas de cobertura; $\mathrm{SD}+\mathrm{PC}=$ solo degradado com plantas de cobertura, $\mathrm{C}=$ campo nativo; $\mathrm{SD}=$ solo degradado. Médias seguidas pela mesma letra na coluna não diferem estatisticamente entre si pelo teste de Duncan em nível de 5\% de probabilidade de erro.

protetor. Neste caso, o efeito protetor pode ter se expressado em uma diminuição da exposição de raízes e do efeito abrasivo decorrente do transporte de partículas pela erosão eólica sobre as mudas. Melhorias observadas com o uso de plantas de cobertura incluem ainda maior retenção de umidade no solo, amenização da amplitude térmica e proteção contra erosão (SEGANFREDO et al., 1997), o que favorece o desenvolvimento vegetal (BRAGAGNOLO \& MIELNICZUK, 1990; BORTOLUZI \& ELTZ, 2000). Nos tratamentos com cobertura herbácea mais densa, campo (C) e campo com plantas de cobertura (C+PC), encontraram-se índices menores de crescimento do eucalipto, quando comparados aos do tratamento SD + PC, principalmente aos 12 meses após o plantio. Isso demonstra que pode ter ocorrido o estabelecimento de competição interespecífica nos dois primeiros. DINARDO et al. (1998), avaliando a interferência da Brachiaria decumbens sobre o crescimento inicial do Eucalyptus grandis, observaram que este apresentou reduções de $30 \%$ em altura, de $71 \%$ no número de folhas e de $47 \%$ no número de ramos, quando comparado com a testemunha sem competição.

Aos 12 meses, o pínus apresentou melhores resultados no tratamento SD. O menor crescimento nos tratamentos com cobertura vegetal demonstra maior sensibilidade à competição interespecífica.
Principalmente aos 12 meses, este foi o tratamento em que o pínus apresentou maior crescimento. O fator de produtividade é o parâmetro que melhor representa este resultado. MORRIS et al. (1993), avaliando a interferência da competição sobre um povoamento de pínus, concluíram que altura, diâmetro e volume das árvores apresentaram tendência de redução para todos os tratamentos com competição. Entretanto, apresentaram diferenças significativas apenas para a variável volume, com as maiores reduções ocorrendo nos tratamentos com competidores herbáceos, em comparação aos tratamentos com competidores arbóreos. CANTARELI (2002), avaliando a influência da cobertura herbácea em povoamentos de Pinus elliottii, não encontrou diferenças significativas entre os tratamentos com controle químico total e controle químico na linha, contudo, estes diferiram da testemunha sem controle, a qual apresentou menores médias em altura, diâmetro à altura do colo e fator de produtividade.

Tanto para o eucalipto quanto para o pínus, as diferenças entre os tratamentos acentuam-se a partir dos seis meses. A avaliação aos 30 dias demonstrou uma maior uniformidade entre tratamentos, ou seja, até esta época, os efeitos das coberturas vegetais, ou da ausência desta, no caso do solo degradado (tratamento $\mathrm{SD}$ ), não foram tão decisivos. O fato de o pínus apresentar valores de diâmetro à altura do colo, altura e fator de produtividade superiores ao eucalipto, aos 
30 dias, está relacionado com as dimensões com que as mudas saíram do viveiro. No momento do plantio, as mudas de eucalipto apresentavam diâmetro médio à altura do colo de 0,032cm e altura média de 39,4cm. Já as mudas de pínus apresentavam um diâmetro à altura do colo de $0,4 \mathrm{~cm}$ e altura média de $41,3 \mathrm{~cm}$.

De uma maneira geral, o pínus, comparativamente ao eucalipto, apresentou maiores dificuldades em adaptar-se às condições simuladas pelos tratamentos. Considerando-se apenas os resultados obtidos aos 12 meses após o plantio, em relação ao diâmetro à altura do colo, o eucalipto apresentou crescimento $68 \%$ maior que o pínus quando estabelecido no campo nativo com plantas de cobertura, 73\% maior no solo degradado com plantas de cobertura; 58 e $61 \%$ maior no campo nativo e no solo degradado, respectivamente. Já em altura, o crescimento do eucalipto foi $70 \%$, 81\%, 70\% e $65 \%$ maior que o do pínus, para os tratamentos nesta mesma ordem. Avaliando o fator de produtividade, as diferenças foram ainda mais acentuadas. $\mathrm{O}$ fator de produtividade do eucalipto sobre o campo nativo com plantas de cobertura foi $97 \%$ maior que o do pínus, 98\% maior sobre o solo degradado com plantas de cobertura, 92\% maior sobre o campo nativo e 95\% maior sobre o solo degradado. Diversas pesquisas têm demonstrado o potencial do eucalipto para desenvolver-se em condições desfavoráveis do meio, tais como solos degradados e/ou solos excessivamente arenosos, devido à sua tolerância à estresse hídrico, à baixa fertilidade e à elevada acidez do solo (SOUTO, 1984; LESLE et al., 2001).

O fato de o eucalipto e de o pinus terem, ambos, apresentado melhor crescimento sobre duas situações que envolvem o solo degradado (SD + PC e $\mathrm{SD}$ ), contraria a hipótese inicial de que se poderia alcançar melhores resultados implantando o povoamento no campo ao redor do areal, devido às condições do campo serem mais adequadas quanto a umidade, temperatura e matéria orgânica. Dessa forma, o povoamento pode ser feito a partir da área degradada e, se possível, em consórcio com uma planta de cobertura de crescimento rápido, para diminuir os efeitos da abrasão ocasionadas pelos sedimentos em suspensão na erosão eólica e exposição de raízes. Uma alternativa possível é promover o crescimento da cultura de cobertura antes da implantação das espécies florestais. Como o objetivo da revegetação em áreas de arenização é amenizar os efeitos da erosão eólica e conter a expansão do núcleo de degradação, práticas silviculturais, como o coroamento da muda, não são aconselháveis. Face ao baixo grau de agregação do solo arenoso, a potencialidade de retirada da cobertura vegetal pela ação erosiva é muito grande. A prática de dessecação na linha de plantio pode ser aconselhada como alternativa para obter-se uma melhor taxa de crescimento do povoamento florestal.

\section{CONCLUSÕES}

O eucalipto e o pínus apresentaram boa adaptação às condições desfavoráveis para o crescimento vegetal em solos afetados pela arenização.

A influência da competição interespecífica no tratamento Campo + Plantas de Cobertura foi mais prejudicial ao crescimento das plantas do que as condições ambientais desfavoráveis do solo degradado, sendo o pínus mais sensível a esta competição do que o eucalipto, tanto em sobrevivência das mudas, quanto em crescimento das plantas.

O uso do eucalipto para a contenção da arenização pode ser iniciado sobre o solo já arenizado e em consórcio com plantas de cobertura. Já no plantio do pínus, deve-se ter maior cuidado com consórcio com espécies herbáceas, devido à competição interespecífica.

\section{AGRADECIMENTOS}

À Fundação Maronna, de Alegrete, RS, e ao Eng. Agr. Ivo Mello, pelo apoio e suporte logístico durante a condução do experimento.

Ao Pesquisador da Embrapa/CPACT, Eng. Agr. MSc. Carlos Alberto Flores, e ao Professor da Universidade Federal de Pelotas, RS, Eng. Agr. Dr. Vilmar Luciano Mattei, pela colaboração no desenvolvimento desta pesquisa.

À Coordenação de Aperfeiçoamento de Pessoal de Nível Superior (CAPES), pela concessão de bolsa à pesquisadora Ana Paula Moreira Rovedder, e ao Conselho Nacional de Desenvolvimento Científico e Tecnólogico (CNPq), pela concessão de bolsa ao pesquisador Flávio Luiz Foletto Eltz.

\section{REFERÊNCIAS}

AB'SABER, A.N. A revanche dos ventos. Destruição dos solos areníticos e formação de areais na Campanha Gaúcha. Ciência \& Ambiente, v.11, p.7-31, 1995.

BORTOLUZI, E.C.; ELTZ, F.L.F. Efeito do manejo mecânico da palhada de aveia preta sobre a cobertura, temperatura, teor de água no solo e emergência da soja em sistema plantio direto. Revista Brasileira de Ciência do Solo, v.24, n.2, p.449457, 2000 .

BRAGAGNOLO, N.; MIELNICZUK, J. Cobertura do solo por palha de trigo e seu relacionamento com a temperatura e umidade do solo. Revista Brasileira de Ciência do Solo, v.14, p.8184, 1990.

CANTARELI, E.B. Efeito da cobertura e períodos de manejo de plantas daninhas no desenvolvimento inicial de Pinus elliottii, Pinus taeda e Pinus elliottii var. elliottii $\mathrm{x}$ 
Pinus caribaea $\mathbf{x}$ hondurensis. 2002. 89f. Dissertação (Mestrado em Engenharia Florestal) - Programa de Pósgraduação em Engenharia Florestal, Universidade Federal de Santa Maria.

COSTA, L.M. Manejo de solos em áreas reflorestadas. In: BARROS, N.F.; NOVAIS, R.F. Relação solo-eucalipto. Viçosa: Universidade Federal de Viçosa, 1990. Cap.6, p.237-263.

DIAS, L.E.; GRIFFITH, J.J. Conceituação e caracterização de áreas degradadas. In: Recuperação de áreas degradadas. Viçosa, MG, 1998. V.1, p.1-7.

DINARDO, W. et al. Interferência da palhada de capimbraquiária sobre o crescimento inicial do eucalipto. Planta Daninha, v.16, n.1, p.13-23, 1998.

EMBRAPA. Centro Nacional de Pesquisas de Solos. Sistema brasileiro de classificação de solos. Rio de Janeiro: Embrapa, 1999. 412p.

KLAMT, E.; SCHNEIDER, P. Solos suscetíveis à erosão eólica e hídrica na região da Campanha do Rio Grande do Sul. Ciência \& Ambiente, v.11, p.71-80, 1995.

LESLE, P.S.S. et al. Crescimento, produção e alocação de matéria seca de Eucalyptus camaldulensis e Eucalyptus pellita sob diferentes espaçamentos na região de cerrado, MG. Scientia forestalis, n.59, p.77-87, 2001.

LIMA, W.P. Impacto ambiental do eucalipto. 2.ed. São Paulo: Universidade de São Paulo, 1996. 301p.

MEDEIROS, E. et al. Degradação ambiental na região sudoeste do Rio Grande do Sul. Ciência \& Ambiente, v.11, p.53-64, 1995

MONTENEGRO, P.A. Efecto del periodo y cobertura del control de malezas en el desarrollo de plantaciones de Pinus taeda I. 1998. 110f. Tesis (Grado en Agronomia) Universidad del Salvador, Faculdad de Agronomia. Argentina.
MORRIS, L.A. et al. Competitive interference between selected herbaceous and woody plants and Pinus taeda L. during two growing seasons following planting. Forest Science, v.39, n.1, p.166-187, 1993.

RESENDE, A.V.; KONDO, M.K. Leguminosas e recuperação de áreas degradadas. Informe Agropecuário, v.22, n.210, p.46-56, 2001

ROVEDDER, A.P.M. Revegetação com culturas de cobertura e espécies florestais para a contenção do processo de arenização em solos areníticos no sudoeste do Rio Grande do Sul. 2003. 120f. Dissertação (Mestrado em Agronomia) - Programa de Pós-graduação em Agronomia, Universidade Federal de Santa Maria.

SCHREINER, H.G.; BALLONI, E.A. Consórcio das culturas de feijão (Phaseolus vulgaris L.) e Eucalyptus grandis W. Hill ex Maiden) no sudeste do Brasil. Curitiba: Empresa Brasileira de Pesquisa Agropecuária, 1986. p.83-104. 104p. (Boletim de Pesquisa Florestal, 12).

SEGANFREDO, M.I. et al. Perdas de solo, água e nutrientes por erosão em sistemas de culturas em plantio direto. Revista Brasileira de Ciência do Solo, v.21, n.2, p.287-291, 1997.

SILVA, D.M. et al. Densidade populacional da fauna edáfica em diferentes áreas da depressão central do estado do Rio Grande do Sul. In: CONGRESSO BRASILEIRO DE CIÊNCIA DO SOLO, 28., 2001, Londrina, PR. Anais... Londrina: Sociedade Brasileira de Ciência do Solo, 2001. 367p. p.66.

SOUTO, J.J. Deserto, uma ameaça? Porto Alegre: Secretaria da Agricultura, 1984. 169p.

SUERTEGARAY, D.M. O Rio Grande do Sul descobre os seus desertos. Ciência \& Ambiente, n.11, p.33-52, 1995.

SUERTEGARAY, D.M.A. Deserto grande do sul: controvérsia. Porto Alegre: UFRGS, 1998. 130p. 